\title{
Immune-related Adverse Effects and Outcome of Patients With Cancer Treated With Immune Checkpoint Inhibitors
}

\author{
ONDREJ FIALA ${ }^{1,2}$, ONDREJ SOREJS ${ }^{1,2}$, JAN SUSTR $^{1}$, RADEK KUCERA $^{3}$, \\ ONDREJ TOPOLCAN ${ }^{3}$ and JINDRICH FINEK ${ }^{1}$ \\ ${ }^{1}$ Department of Oncology and Radiotherapeutics, Medical School and University Hospital in Pilsen, \\ Charles University, Pilsen, Czech Republic; \\ ${ }^{2}$ Biomedical Center, Faculty of Medicine in Pilsen, Charles University, Pilsen, Czech Republic; \\ ${ }^{3}$ Department of Immunochemistry Diagnostics, Medical School and University Hospital in Pilsen, \\ Charles University, Pilsen, Czech Republic
}

\begin{abstract}
Immunotherapy based on immune checkpoint inhibitors (ICIs) represents a novel anticancer treatment strategy. Monoclonal antibodies targeting cytotoxic T-lymphocyte antigen4 (CTLA4), programmed cell death-1 receptor (PD1) and programmed cell death-1 ligand (PD-L1) have shown efficacy and safety in the treatment of various malignancies. Some of them have recently found their place in a routine clinical practice, while others are at different phases of clinical trials. Treatment with ICIs may be accompanied by undesirable impairment of immunotolerance to non-tumoural tissues, leading to a specific side-effect also called immune-related adverse events (irAE). There is an increasing body of evidence that the development of irAEs is associated with a beneficial effect of immunotherapy, thus it has become a hot topic in the field of clinical oncology. This review is focused on data from recently published studies evaluating the association between irAEs and outcome of patients with cancer treated with ICIs.
\end{abstract}

Immunotherapy based on the blocking of immune checkpoints represents an innovative anticancer treatment strategy that has been currently changing the world of clinical oncology. There are several agents that have shown efficacy and safety in the

This article is freely accessible online.

Correspondence to: Ondrej Fiala, MD, Ph.D., Department of Oncology and Radiotherapy, Medical School and University Hospital Pilsen, Charles University Prague, alej Svobody 80, CZ30460 Pilsen, Czech Republic. Tel: +42 0728655488, e-mail: fiala.o@centrum.cz

Key Words: Immunotherapy, checkpoint inhibitor, adverse effects, outcome, efficacy, review. treatment of various malignancies. Some of them have recently found their place in a routine clinical practice, while others are at different phases of clinical trials. Among the malignancies where ICIs have been well established and have already been widely used in the routine clinical practice include malignant melanoma (MM), lung cancer and renal cell carcinoma (RCC). Furthermore, ICIs show efficacy and have been approved for the treatment of urothelial carcinoma, breast, head and neck squamous cell cancer, gastric cancer, hepatocellular cancer, colorectal cancer with microsatellite instability, Hodgkin lymphoma and Merkel cell carcinoma (1-12).

The most frequently used immune checkpoint inhibitors (ICIs) are monoclonal antibodies against cytotoxic T-lymphocyte antigen-4 (CTLA4), programmed cell death-1 receptor (PD1) and programmed cell death-1 ligand (PD-L1). The most commonly studied CTLA4 inhibitor is ipilimumab; among PD1 inhibitors, nivolumab, pembrolizumab and avelumab; among PD-L1 inhibitors, atezolizumab and durvalumab.

In contrast to chemotherapy or targeted therapies, immunotherapy has several specific characteristics in terms of the clinical response and side-effects. Overcoming tumour immunotolerance induced by ICIs may be accompanied by undesirable impairment of immunotolerance to non-tumoural tissues. The consequence of this is the emergence of specific side-effects also called immune-related adverse events (irAE). The nature of irAEs is similar to an autoimmune disease. These are to a large extent typical for immunotherapy. In general, irAEs can be divided into organ-specific and organ non-specific; according to the timing of onset they can be divided into early and late. IrAEs can result in damage of any organ, including the skin, intestines, liver, kidneys, lungs, eyes, endocrine glands, heart, muscle, and central or peripheral nervous system (13-15). The most commonly seen are dermatological and gastrointestinal irAEs. 
There is an increasing body of evidence that the development of irAEs is associated with a beneficial effect of immunotherapy (16). This association has been described so far in malignancies for which there is the greatest experience with immunotherapy, including MM, non-small cell lung cancer (NSCLC) and RCC.

\section{IrAEs and Outcome in MM}

The association between irAEs and the efficacy of ICIs was first reported in patients with advanced-stage MM. The published data on treatment with CTLA4 (ipilimumab) and PD1 (nivolumab, pembrolizumab) inhibitors are not entirely consistent.

The first retrospective analysis of patients with metastatic MM ( $n=56)$ treated with ipilimumab which was conducted by Attia et al. showed that $36 \%$ of patients with grade 3-4 irAEs reached an objective response to the therapy (ORR), whereas among patients without or with a low-grade irAEs, only $5 \%$ had a treatment response $(p=0.008)(17)$. These results were subsequently confirmed by a combined analysis of the data obtained from two prospective clinical trials $(n=139)$, which showed that irAEs of any grade in patients with metastatic MM treated with ipilimumab were significantly associated with ORR $(p=0.0004)$ and a significantly longer duration of response was observed in patients with grade 3-4 irAEs as compared to those with low-grade irAEs (34 vs. 11 months) (18). Nevertheless, the study showed that the duration of treatment response was not adversely affected by the use of high doses of corticosteroids to treat irAEs $(p=0.23)(18)$. On the other hand, two retrospective analyses of larger patient cohorts treated with ipilimumab $(n=833$ and $n=298$, respectively) did not show any significant association between irAEs and outcome $(19,20)$. However, the retrospective design of these studies potentially conferring a bias in the form of underestimation and grade underscoring of irAEs should be emphasized $(19,20)$.

Several studies have shown the impact of specific types of irAEs. A significant association between development of vitiligo and survival was observed in a meta-analysis of published studies in patients with advanced MM treated with various immunotherapy strategies, which was conducted by Teulings et al. (21). Their results showed that vitiligo was associated with longer progression-free survival (PFS) and overall survival (OS) [hazard ratio $(\mathrm{HR})=0.51, p=0.005$ and $\mathrm{HR}=0.25, p=0.003$, respectively] (21). Similar results have been reported in patients with metastatic MM treated with high-dose interferon or highdose interleukin-2 (22, 23). Endocrine irAEs, most frequently in the form of hypopituitarism or hypothyroidism, represent another specific type of irAE whose incidence is described in association with a beneficial effect of immunotherapy with ICIs. Fujisawa et al. observed a significant association of endocrine irAEs with OS in patients with unresectable or metastatic MM $(\mathrm{n}=60)$ treated with ipilimumab $(\mathrm{HR}=0.22, p=0.015)(24)$. A pooled analysis of safety data of nivolumab obtained from four prospective clinical trials in patients with advanced MM ( $\mathrm{n}=576)$ showed a significantly higher ORR in patients with irAEs of any grade (48.6 vs. $17.8 \%$, $p<0.0001)$ (25). Similarly, in a small retrospective study including patients with advanced MM treated with nivolumab $(\mathrm{n}=15)$, Okada et al. reported a higher disease control rate (DCR) $(75 \%$ vs. $14 \%, p<0.05)$ and longer OS $(p<0.05)$ in patients with any irAE compared to those without (26). A retrospective study focusing on the role of irAEs in patients with resected and unresectable MM $(n=148)$ treated with nivolumab was conducted by FreemanKeller et al. (27). They found a significantly longer OS in patients who experienced an irAE versus those who did not $(p<0.001)$, while the OS benefit was noted in patients who reported three or more irAE events $(p<0.001)$ (27). Moreover, a 12-week landmark survival analysis closely focusing on the role of specific type of irAEs found that only skin rash and vitiligo were significantly associated with OS $(p=0.0004$ and $p=0.028)$, while no statistically significant differences in OS were seen in patients with any grade of hypothyroidism $(p=0.117)$, hyperthyroidism $(p=0.489)$, diarrhoea $(p=0.132)$, or pneumonitis $(p=0.493)$ (27). Another retrospective study by Maeda et al. also recorded a significant association of endocrine irAEs with DCR ( $84.6 \%$ vs. $37.5 \%, p=0.004)$ in patients treated with nivolumab for metastatic MM $(n=69)$; there was also a trend for longer PFS in the 20-week landmark analysis, however, it was not statistically significant $(p=0.07)(28)$. The data published on the linkage between irAEs and outcome in patients treated with pembrolizumab are still limited, however, several studies suggest similar results to those obtained from studies with nivolumab. The retrospective study conducted by Indini et al. including patients with metastatic MM $(n=173)$ treated with pembrolizumab or nivolumab found a higher DCR $(p=0.029)$ and longer PFS and $\mathrm{OS}$ in patients with any irAE in the multivariate Cox regression analysis $(\mathrm{HR}=0.47, p=0.016 ; \mathrm{HR}=0.39, p=0.007)$ (29). Analysis of prospectively collected data from patients with advanced MM treated with pembrolizumab $(n=147)$ found a higher DCR in patients who developed any irAE ( 75.0 vs. 17.9\%, $p=0.02$ ) and the best results were achieved in patients with higher grade irAEs, in whom a significantly longer PFS and OS were found compared to patients without irAEs $(\mathrm{HR}=0.54, p<0.001 ; \mathrm{HR}=0.51$, $p<0.001)$ (30). There was no significant association between the use of corticosteroids and PFS nor OS ( $p=0.8$ and $p=0.6$, respectively) (30). The results of selected studies on patients with MM are summarised in Table I. 
Table I. Summary of selected studies in patients with malignant melanoma.

\begin{tabular}{|c|c|c|c|c|c|}
\hline Authors (Ref) & Year & $\begin{array}{l}\text { Immune } \\
\text { checkpoint } \\
\text { inhibitor }\end{array}$ & $\begin{array}{l}\text { Study } \\
\text { design }\end{array}$ & $\begin{array}{l}\text { Patients, } \\
\mathrm{n}\end{array}$ & Results \\
\hline Attia et al. (17) & 2005 & Ipilimumab & Retrospective & 56 & $\begin{array}{l}\text { - Higher ORR in patients with grade 3-4 irAEs } v s \text {. those } \\
\text { without or with a low-grade irAEs }(36 \% v s .5 \%, p=0.008) \text {. }\end{array}$ \\
\hline Downey et al. (18) & 2007 & Ipilimumab & Retrospective & 139 & $\begin{array}{l}\bullet \text { Higher ORR in patients with irAEs } v s \text {. those without } \\
\text { (grade 3/4: } 28 \% v s \text {. grade } 1 / 2: 22 \% v s \text {. no irAEs: } 2 \%, p=0.0004 \text { ). }\end{array}$ \\
\hline Ascierto et al. (19) & 2014 & Ipilimumab & Retrospective & 855 & $\begin{array}{c}\text { - No difference in DCR between patients with irAEs of } \\
\text { any grade and those without }(35 \% \text { vs. } 34 \%) \text {. } \\
\text { - No difference in OS between patients with irAEs of any } \\
\text { grade and those without after adjusting for the } \\
\text { number of doses completed (10.1 vs. } 9.7 \text { months). }\end{array}$ \\
\hline Horvat et al. (20) & 2015 & Ipilimumab & Retrospective & 298 & - No association of irAEs with TTF and OS. \\
\hline Teulings et al. (21) & 2016 & $\begin{array}{l}\text { Various } \\
\text { immunotherapy } \\
\text { strategies }\end{array}$ & Meta-analysis & 5,737 & $\begin{array}{l}\bullet \text { Vitiligo was associated with longer PFS } \\
(\mathrm{HR}=0.51, p=0.005) \text { and } \mathrm{OS}(\mathrm{HR}=0.25, p=0.003) \text {. }\end{array}$ \\
\hline $\begin{array}{l}\text { Freeman-Keller } \\
\text { et al. }(27)\end{array}$ & 2016 & Nivolumab & Retrospective & 148 & $\begin{array}{c}\bullet \text { Longer OS for patients with any irAEs } \\
v s \text {. those without irAEs }(p<0.001) \\
\text { - Skin rash and vitiligo were associated with OS }(p=0.0004 \\
\text { and } p=0.028) \text { in a } 12 \text {-week landmark survival analysis. } \\
\text { - No association of OS with other irAEs (endocrinopathies, colitis, } \\
\text { pneumonitis) in a 12-week landmark survival analysis. }\end{array}$ \\
\hline Weber et al. (25) & 2017 & Nivolumab & Retrospective & 576 & $\begin{array}{c}\cdot \text { Higher ORR in patients with any irAEs compared } \\
\text { to those without }(48.6 v s .17 .8 \%, p<0.0001)\end{array}$ \\
\hline Fujisawa et al. (22) & 2018 & Ipilimumab & Retrospective & 60 & $\begin{array}{c}\cdot \text { Endocrine irAEs are associated with } \\
\text { longer OS }(\mathrm{HR}=0.22, p=0.015)\end{array}$ \\
\hline Okada et al. (26) & 2018 & Nivolumab & Retrospective & 15 & $\begin{array}{l}\text { - Higher DCR in patients with any irAE }(p<0.05) \text {. } \\
\text { - Longer OS in patients with any irAE }(p<0.05) \text {. }\end{array}$ \\
\hline Maeda et al. (28) & 2018 & Nivolumab & Retrospective & 69 & $\begin{array}{l}\text { - Higher DCR in patients with endocrine } \\
\text { irAEs }(84.6 \% \text { vs. } 37.5 \%, p=0.004) \text {. } \\
\text { - Trend for longer PFS in patients with endocrine irAEs } \\
(p=0.07) \text { in the } 20 \text {-week landmark analysis. }\end{array}$ \\
\hline Indini et al. (29) & 2018 & $\begin{array}{l}\text { Pembrolizumab } \\
\text { or nivolumab }\end{array}$ & Retrospective & 173 & $\begin{array}{c}\text { - Higher DCR in patients with any irAE }(p<0.029) \text {. } \\
\text { - Longer PFS and OS in patients with any irAE in the } \\
\text { multivariate Cox regression analysis }(\mathrm{HR}=0.47, \\
p=0.016 \text {; and HR }=0.39, p=0.007 \text {, respectively). } \\
\text { - Vitiligo was significantly associated with OS }(p=0.003) \text {. }\end{array}$ \\
\hline Bisschop et al. (30) & 2019 & Pembrolizumab & Retrospective & 147 & $\begin{array}{l}\cdot \text { Higher DCR in patients with any irAE }(75.0 v s .17 .9 \%, p=0.02) \text {. } \\
\qquad \text { Longer PFS and OS in patients with high-grade irAEs in } \\
\text { multivariate Cox regression analysis (HR=0.54, } \\
\qquad p<0.001 ; \mathrm{HR}=0.51, p<0.001) \\
\text { - No significant association between the use of corticosteroids } \\
\text { and PFS or OS ( } p=0.8 \text { and } p=0.6 \text {, respectively). }\end{array}$ \\
\hline
\end{tabular}

irAE: Immune-related adverse effect; ORR: objective response rate; DCR: disease control rate; PFS: progression-free survival; TTF: time to treatment failure; OS: overall survival; HR: hazard ratio.

\section{IrAEs and Outcome in NSCLC}

In patients with advanced and metastatic NSCLC, the association of irAEs with the effect of immunotherapy has been documented particularly in treatment with anti-PD1 and anti-PD-L1 inhibitors, which are commonly used in advanced NSCLC.

The association of the effect of nivolumab with irAE in patients with metastatic NSCLC $(n=40)$ was first reported by
Hasan Ali et al., who observed the association of treatment response with skin toxicity (31). Skin irAEs were associated with ORR (42\% in patients with skin irAEs vs. $7 \%$ in those without) (31). Sato et al. observed that irAEs were associated with longer PFS $(\mathrm{HR}=0.10, p<0.001)$ in patients with advanced NSCLC treated with nivolumab $(n=38)$, however, subsequent 60-day landmark analysis did not show any significant difference $(\mathrm{HR}=0.28, p=0.13)(32)$. Longer OS in patients with metastatic NSCLC $(n=91)$ who developed any 
irAEs during the course of nivolumab treatment as compared to those with no irAEs $(\mathrm{HR}=2.75, p<0.001)$ was reported by Owen et al. (33). They did not observe significant differences in a 3-month landmark analysis, which was similar to the study by Sato et al. (32). Another retrospective analysis of patients with advanced NSCLC treated with nivolumab $(\mathrm{n}=134)$ showed higher ORR $(52.3 \%$ vs. $27.9 \%$, $p=0.02$ ) in patients with any irAE; moreover, in a Cox multivariable analysis, irAEs remained a significant factor for longer PFS $(\mathrm{HR}=0.542, p=0.04)$ as well as for OS (HR=0.285, $p=0.003$ ) (34). Regarding the specific type of irAE, skin irAEs were significantly associated with longer PFS (HR=0.476, $p=0.03$ ) and OS (HR=0.209, $p=0.003)$, and endocrine irAEs were significantly associated with longer PFS (HR=0.237, $p=0.02)(34)$.

The prognostic role of irAEs developing early after initiation of nivolumab treatment was demonstrated in the analysis of prospective data of patients with advanced NSCLC $(n=43)$ conducted by Teraoka et al. (35). They found a significant correlation of longer PFS with any irAE $(p=0.01)$ and irAE in the form of skin rash $(p=0.01)$ in a 2week landmark analysis (35). By shifting the boundary of the landmark analysis to 6 weeks, the differences in PFS were no longer significant but there was a significant trend for both parameters $(p=0.06$ and $p=0.08)$; the shift beyond statistical significance might have been affected by a small group of patients (35). Subsequently, two larger retrospective studies were published. The study conducted by Ricciuti et al., including patients with advanced NSCLC treated with nivolumab $(\mathrm{n}=195)$, showed significantly higher ORR (43.5\% vs. $10.0 \%, p<0.0001)$ and DCR $(70.5 \%$ vs. $18.1 \%$, $p<0.0001)$, as well as longer PFS and OS $(\mathrm{HR}=0.41$, $p<0.0001$ and $\mathrm{HR}=0.33, p<0.0001)$ in patients with irAEs compared with patients without any (36). The results of the Cox multivariate model showed the following factors to be significant for PFS: any $\operatorname{irAE}(\mathrm{HR}=0.48, p<0.0001)$, pulmonary $(\mathrm{HR}=0.56, p=0.038)$, gastrointestinal $(\mathrm{HR}=0.055$, $p=0.021)$, endocrine $(\mathrm{HR}=0.59, p=0.011)$ and skin irAEs (HR=0.57, $p=0.031)$; significant factors for OS were: any irAE $(\mathrm{HR}=0.38, p<0.0001)$, pulmonary $(\mathrm{HR}=0.46, p=0.022)$, gastrointestinal $(\mathrm{HR}=0.50, p=0.045)$, endocrine $(\mathrm{HR}=0.45$, $p=0.001)$ and skin irAEs $(\mathrm{HR}=0.80, p=0.043)$ (36). A 6weeks landmark analysis showed a significant association of irAEs with $\mathrm{OS}(\mathrm{HR}=0.55, p=0.021)$ and a 12-weeks landmark analysis showed an even deeper and statistically significant association with PFS $(\mathrm{HR}=0.48, p<0.0001)$ and OS $(H R=0.40, p<0.0001)(36)$. The results of the study also showed longer PFS and OS in patients with two or more types of irAEs versus those with only one versus those without any irAE (PFS: 8.5 vs. 4.6 vs. 2.0 months, $p<0.0001$; OS: $26.8 v s .11 .9 v s .4 .0$ months, $p<0.0001)(36)$.

The association of the incidence of irAEs with the effect of anti-PD1 (nivolumab, pembrolizumab) and anti-PD-L1 (atezolizumab) inhibitors in patients with advanced NSCLC $(n=270)$ was recently confirmed by a retrospective study by conducted by Grangeon et al. (37). The results of this study showed a significant association between the incidence of irAEs and higher ORR (22.9\% vs. 5.7\%, p<0.0001), DCR (72.4\% vs. 36.7\% $p<0.001)$ as well as longer PFS $(\mathrm{HR}=0.42$, $p<0.001)$ and $\mathrm{OS}(\mathrm{HR}=0.29, p<0.001)$ (37). The study confirmed a significant association of irAE in a form of hypothyroidism with longer PFS $(\mathrm{HR}=0.56, p=0.005)$ and OS $(\mathrm{HR}=0.46, p=0.01)$ and did not show significant differences according to the grade of irAEs (37). The association of immune-related thyroid dysfunction with effect of ICIs has been observed also in two other studies by Osorio et al. (38) and Toi et al. (39). Moreover, both studies reported that the development of thyroid dysfunction was significantly higher in patients with pre-existing antithyroid antibodies than in those without $(80 \%$ vs. $8 \%, p<0.0001$; and $40 \%$ vs. $2 \%, p<0.001$, respectively) $(38,39)$.

The largest study focused on the association of irAEs with ICI treatment efficacy to date was recently conducted by Cortellini et al. (40). Their retrospective study included 559 patients with advanced NSCLC treated with nivolumab or pembrolizumab (40). The results of a multivariate analysis showed a higher ORR was related to experiencing any irAE $(p<0.0001)$, and endocrine $(p=0.0043)$ and skin $(p=0.0005)$ irAEs; significantly longer PFS was associated with irAEs of any grade $(p<0.0001)$, endocrine $(p=0.0084)$ and skin $(p=0.0001)$; and significantly longer OS was associated with irAEs of any grade $(p<0.0001)$, endocrine $(p=0.0044)$, gastrointestinal $(p=0.0437)$, and skin $(p=0.0006)$ irAEs. The 6 -weeks landmark analysis revealed irAEs of any grade as an independent predictive factor for higher ORR, and longer PFS and OS (40). The results of selected studies on patients with NSCLC are summarised in Table II.

\section{IrAEs and Outcome in RCC}

As compared to MM and NSCLC, the data on the relationship between irAEs and outcome of patients with advanced RCC treated with ICIs are limited to several recently published retrospective studies. The study conducted by Ishihara et al. $(\mathrm{n}=47)$ showed significantly higher ORR (60.9\% vs. $12.5 \%, p=0.0006)$, and longer PFS $(p<0.0001)$ and OS $(p=0.0072)$ in patients with irAEs as compared to those without (41). The Cox multivariate model confirmed the occurrence of irAEs as an independent factor for better PFS (HR=0.25, $p=0.0009)$; OS analysis was not performed (41). A landmark analysis after two cycles of treatment (i.e. after 1 month of the treatment) showed significant association only for PFS ( $p=0.0279)$; for OS the difference was not statistically significant $(p=0.193)$. Regarding the grade of irAEs, PFS was significantly longer both in patients with grade 1-2 irAEs $(p=0.0024)$ and those with grade 3 or 
Table II. Summary of selected studies in patients with non-small cell lung cancer.

\begin{tabular}{|c|c|c|c|c|c|}
\hline Authors (Ref) & Year & $\begin{array}{l}\text { Immune } \\
\text { checkpoint } \\
\text { inhibitor }\end{array}$ & $\begin{array}{l}\text { Study } \\
\text { design }\end{array}$ & $\begin{array}{c}\text { Patients, } \\
\mathrm{n}\end{array}$ & Results \\
\hline Hasan Ali et al. (31) & 2016 & Nivolumab & Retrospective & 40 & $\begin{array}{l}\text { - Skin irAEs were associated with ORR ( } 42 \% \text { in patients } \\
\text { with skin irAEs vs. } 7 \% \text { in those without). }\end{array}$ \\
\hline Teraoka et al. (35) & 2017 & Nivolumab & Prospective & 43 & $\begin{array}{l}\text { - Longer PFS in patients with any irAEs }(p=0.01) \\
\text { in a } 2 \text {-weeks landmark analysis. } \\
\text { - Longer PFS in patients with skin rash }(p=0.01) \\
\text { in a } 2 \text {-weeks landmark analysis. }\end{array}$ \\
\hline Osorio et al. (38) & 2017 & Pembrolizumab & Retrospective & 51 & $\begin{array}{l}\text { - Thyroid dysfunction was significantly higher in } \\
\text { patients with pre-existing antithyroid antibodies } \\
\text { vs. those without }(80 \% \text { vs. } 8 \%, p<0.0001) \text {. } \\
\text { • Longer OS in patients who developed } \\
\text { thyroid dysfunction (HR }=0.29, p=0.04) \text {. }\end{array}$ \\
\hline Haratani et al. (34) & 2018 & Nivolumab & Retrospective & 134 & $\begin{array}{l}\text { - Higher ORR in patients with any irAEs }(52.3 \% \text { vs. } 27.9 \%, p=0.02) \text {. } \\
\text { - IrAEs remained a significant factor for longer PFS (HR=0.542, } p=0.04) \\
\text { and also for OS (HR=0.285, } p=0.003 \text { ) in a Cox multivariate analysis. } \\
\text { - Skin irAEs were associated with longer PFS } \\
\quad(\mathrm{HR}=0.476, p=0.03 \text { ) and OS (HR=0.209, } p=0.003) \text {. } \\
\text { - Endocrine irAEs were associated with longer PFS (HR=0.237, } p=0.02) \text {. }\end{array}$ \\
\hline Ricciuti et al. (36) & 2018 & Nivolumab & Retrospective & 195 & 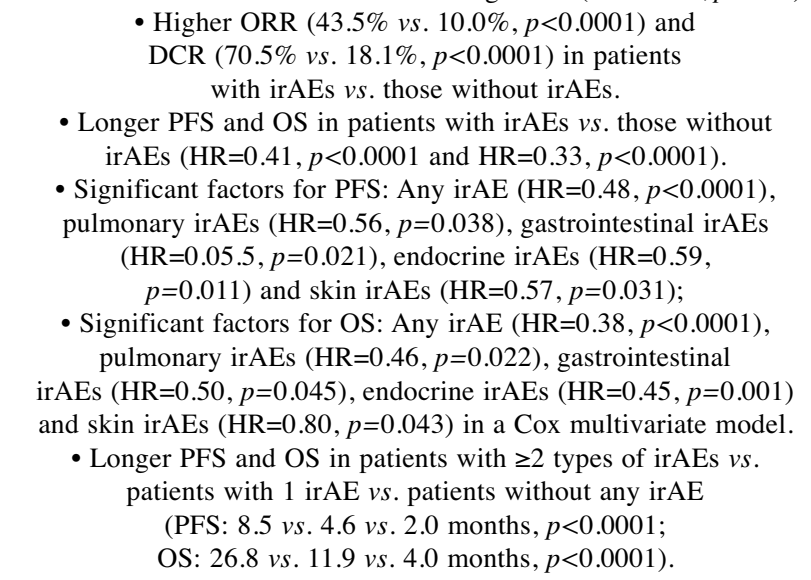 \\
\hline Owen et al. (33) & 2018 & Nivolumab & Retrospective & 91 & $\begin{array}{l}\bullet \text { Longer PFS }(\mathrm{HR}=2.75, p<0.001) \text { in patients with } \\
\text { irAEs } v s . \text { those without irAEs. } \\
\text { - No significant PFS difference in } 3 \text {-months landmark analysis. }\end{array}$ \\
\hline Sato et al. (32) & 2018 & Nivolumab & Retrospective & 38 & $\begin{array}{l}\text { - Longer OS }(\mathrm{HR}=0.10, p<0.001) \text { in patients } \\
\text { with irAEs } v s \text {. those without irAEs. } \\
\text { - No significant OS difference in } 60 \text {-days } \\
\text { landmark analysis }(\mathrm{HR}=0.28, p=0.13)\end{array}$ \\
\hline Toi et al. (39) & 2018 & Nivolumab & Retrospective & 70 & $\begin{array}{l}\text { - Thyroid dysfunction was higher in patients with pre-existing } \\
\text { antithyroid antibodies } v s \text {. those without }(40 \% v s .2 \%, p<0.001) \text {. } \\
\text { • Pre-existing antithyroid antibodies were independent } \\
\text { predictors of ORR (OR=0.22, } p=0.033) \text {. }\end{array}$ \\
\hline Grangeon et al. (37) & 2019 & $\begin{array}{l}\text { Nivolumab, } \\
\text { pembrolizumab, } \\
\text { atezolizumab }\end{array}$ & Retrospective & 270 & $\begin{array}{c}\text { •Higher ORR }(22.9 \% \text { vs. } 5.7 \%, p<0.0001) \text { and DCR } \\
(72.4 \% \text { vs. } 36.7 \% p<0.001) \text { in patients with } \\
\text { irAEs } v s . \text { those without irAEs. } \\
\text { - Longer PFS (HR=0.42, } p<0.001) \text { and OS }(\mathrm{HR}=0.29, p<0.001) \\
\text { in patients with irAEs } v s \text {. those without irAEs. }\end{array}$ \\
\hline Cortellini et al. (40) & 2019 & $\begin{array}{l}\text { Nivolumab, } \\
\text { pembrolizumab }\end{array}$ & Retrospective & 559 & $\begin{array}{c}\bullet \text { Higher ORR in patients with any irAEs }(p<0.0001), \\
\text { endocrine }(p=0.0043) \text { and skin irAEs }(p=0.0005) . \\
\text { - Longer PFS was associated with irAEs of any grade }(p<0.0001) \text {, } \\
\text { endocrine irAEs }(p=0.0084) \text { and skin irAEs }(p=0.0001) \\
\text { - Longer OS was associated with irAEs of any grade }(p<0.0001) \text {, } \\
\text { endocrine irAEs }(p=0.0044) \text {, gastrointestinal irAEs } \\
(p=0.0437) \text {, skin irAEs }(p=0.0006)\end{array}$ \\
\hline
\end{tabular}

irAE: Immune-related adverse effect; ORR: objective response rate; DCR: disease control rate; PFS: progression-free survival; TTF: time to treatment failure; OS: overall survival; HR: hazard ratio; OR: odds ratio. 
more irAEs $(p=0.0023)$ as compared to patients without irAEs; for OS, there was significant correlation only in patients with grade 1-2 irAEs $(p=0.0124)$. With regard to the specific type of irAEs, a significant association with PFS and OS was demonstrated only for skin irAEs $(p=0.011)$ (41). The results of a recently published retrospective study $(\mathrm{n}=389)$ conducted by Verzoni et al . confirmed a significant association of irAEs with OS ( $p=0.01)$; furthermore, irAEs remained an independent factor for OS in a multivariable Cox model (HR=0.57, $p=0.02)$ (42). A 6-week OS landmark analysis showed significant association with irAEs $(p=0.006)$. The results of a 1-year OS analysis found no statistically significant difference between those with grade 1-2 and those with grade 3-4 irAEs $(60.9 \%$ vs. $79.6 \%$, $p=0.19$ ), nor between those with early (occurring within 6 weeks from the treatment initiation) and those with late (occurring over 6 weeks from the treatment initiation) irAEs (78.7\% vs. 85.2\%, $p=0.34$ ) (42); neither ORR nor PFS were evaluated in the study. A development of vitiligo was recently reported in a case of metastatic RCC which achieved a durable complete response after treatment with nivolumab, suggesting this type of irAE to be a factor associated with the efficacy of ICIs in RCC, similarly to that in MM and NSCLC (43).

\section{IrAEs and Outcome in Other Malignancies}

Gastrointestinal cancer. The relationship between irAEs and the efficacy of anti-PD1 therapy in patients $(n=61)$ with various types of advanced gastrointestinal cancer including hepatocellular carcinoma, colorectal cancer with microsatellite instability and gastric cancer was assessed in a retrospective study (44). The study found significantly longer PFS and OS in patients experiencing irAEs as compared to those who not $(p=0.0001$ and $p=0.0036)$ (44). A sub-analysis found no statistically significant differences in PFS nor OS according to the grade, timing of onset or use of corticosteroid therapy (44).

A retrospective study focusing on patients with advanced gastric cancer treated with nivolumab $(n=65)$ conducted by Masuda et al. found significantly longer PFS and OS in patients with irAEs compared to those without $(p<0.001$ and $p<0.001$, respectively) (45). Furthermore, the results of multivariable Cox model demonstrated that absence of irAEs represented an independent factor associated with a poor prognosis $(\mathrm{HR}=9.54, p<0.001)(45)$.

Head and neck cancer. In patients with metastatic head and neck cancer receiving anti-PD1 therapy $(n=114)$, a retrospective study conducted by Foster et al. found higher ORR $(p=0.02)$ and also longer PFS and OS in patients with irAEs compared to those without $(p=0.0004$ and $p=0.007$, respectively) (46). The results of multivariate analyses shown that the development of irAEs was independent factor for improved ORR $(p=0.03)$, PFS $(p=0.009)$, and OS $(p=0.003)(46)$.

Urothelial cancer. In patients with metastatic urothelial cancer, Morales-Barrera et al. reported higher DCR (79\% vs. $36.3 \%, p=0.002)$ and longer OS (21.91 vs. 6.47 months, $p=0.004$ ) for those with irAEs as compared to those without in a single-institution retrospective study $(n=52)(47)$. A pooled analysis of seven randomised clinical trials including cisplatin-refractory or cisplatin-ineligible patients with locally advanced or metastatic urothelial cancer treated with pembrolizumab or atezolizumab $(n=1,747)$ was conducted recently by Maher et al. (48). The study focused on the role of irAEs and adverse events of special interest, which were defined separately from irAEs as autoimmune events not requiring corticosteroid therapy (48). They found longer OS in patients with adverse events of special interest $(\mathrm{HR}=0.45)$ and those with irAEs $(\mathrm{HR}=0.53)$ as compared to those without (48). The duration of response was not affected significantly by the use of corticosteroids in management of irAEs (48).

\section{Conclusion}

There is increasing evidence suggesting that irAEs are associated with treatment response and survival of patients with cancer treated with ICIs. This could be used for the estimation of the prognosis of patients treated with ICIs, suggesting development of irAEs as a feasible on-treatment predictive biomarker. Moreover, this can be helpful information for distinguishing between real progression and pseudoprogression. Most of the published studies are recent, thus it is a hot topic in the field of clinical oncology. However, the vast majority of studies published to date are limited by the relatively low number of patients and retrospective design introducing possible bias. There remain many open questions. The detailed pathophysiological mechanisms underlying various irAEs, as well as the association of specific types of irAEs with the efficacy of ICIs in various cancer types, should be elucidated in the future, optimally under the conditions of prospective clinical trials.

\section{Conflicts of Interest}

OF received honoraria from Roche, GSK and Pfizer for consultations and lectures unrelated to this project. JF has received honoraria from Astra Zeneca, Roche and Novartis for consultations and lectures unrelated to this project. OS, JS, RK and OT declare that they have no actual or potential conflict of interest including any financial, personal or other relationships with other people or organizations that could inappropriately influence this work. 


\section{Authors' Contributions}

OF wrote the article with support from OS, JS, RK, OT and JF.

\section{Acknowledgements}

This study was supported by the National Sustainability Program I (NPU I) Nr. LO1503 provided by the Ministry of Education Youth and Sports of the Czech Republic and by the Charles University Research Fund (Progres Q39) and by the European Regional Development Fund Project "Application of Modern Technologies in Medicine and Industry" (No. CZ.02.1.01/0.0/0.0/17_048/0007280) and by the grant of Ministry of Health of the Czech Republic - 17-30748A.

\section{References}

1 Pennock GK and Chow LQ: The evolving role of immune checkpoint inhibitors in cancer treatment. Oncologist 20(7): 812822, 2015. PMID: 26069281. DOI: 10.1634/theoncologist.20140422

2 La-Beck NM, Jean GW, Huynh C, Alzghari SK and Lowe DB: Immune checkpoint inhibitors: New insights and current place in cancer therapy. Pharmacotherapy 35(10): 963-976, 2015 PMID: 26497482. DOI: 10.1002/phar.1643

3 Robert C, Schachter J, Long GV, Arance A, Grob JJ, Mortier L, Daud A, Carlino MS, McNeil C, Lotem M, Larkin J, Lorigan P, Neyns B, Blank CU, Hamid O, Mateus C, Shapira-Frommer R, Kosh M, Zhou H, Ibrahim N, Ebbinghaus S and Ribas A: Pembrolizumab versus ipilimumab in advanced melanoma. $\mathrm{N}$ Engl J Med 372(26): 2521-2532, 2015. PMID: 25891173. DOI: 10.1056/NEJMoa1503093

4 Robert C, Long GV, Brady B, Dutriaux C, Maio M, Mortier L, Hassel JC, Rutkowski P, McNeil C, Kalinka-Warzocha E, Savage KJ, Hernberg MM, Lebbé C, Charles J, Mihalcioiu C, Chiarion-Sileni V, Mauch C, Cognetti F, Arance A, Schmidt H, Schadendorf D, Gogas H, Lundgren-Eriksson L, Horak C, Sharkey B, Waxman IM, Atkinson $\mathrm{V}$ and Ascierto PA: Nivolumab in previously untreated melanoma without $B R A F$ mutation. N Engl J Med 372(4): 320-330, 2015. PMID: 25399552. DOI: 10.1056/NEJMoa1412082

5 Reck M, Rodríguez-Abreu D, Robinson AG, Hui R, Csőszi T, Fülöp A, Gottfried M, Peled N, Tafreshi A, Cuffe S, O'Brien M, Rao S, Hotta K, Leiby MA, Lubiniecki GM, Shentu Y, Rangwala $\mathrm{R}$ and Brahmer JR: Pembrolizumab versus chemotherapy for PD-L1-positive non-small-cell lung cancer. N Engl J Med 375(19): 1823-1833, 2016. PMID: 27718847.

6 Motzer RJ, Escudier B, McDermott DF, George S, Hammers HJ, Srinivas S, Tykodi SS, Sosman JA, Procopio G, Plimack ER, Castellano D, Choueiri TK, Gurney H, Donskov F, Bono P, Wagstaff J, Gauler TC, Ueda T, Tomita Y, Schutz FA, Kollmannsberger C, Larkin J, Ravaud A, Simon JS, Xu LA, Waxman IM and Sharma P: Nivolumab versus everolimus in advanced renal-cell carcinoma. N Engl J Med 373(19): 18031813, 2015. PMID: 26406148. DOI: 10.1056/NEJMoa1510665

7 Bellmunt J, de Wit R, Vaughn DJ, Fradet Y, Lee JL, Fong L, Vogelzang NJ, Climent MA, Petrylak DP, Choueiri TK, Necchi A, Gerritsen W, Gurney H, Quinn DI, Culine S, Sternberg CN, Mai Y, Poehlein CH, Perini RF and Bajorin DF: Pembrolizumab as second-line therapy for advanced urothelial carcinoma. $\mathrm{N}$
Engl J Med 376(11): 1015-1026, 2017. PMID: 28212060. DOI: 10.1056/NEJMoa1613683

8 Ferris RL, Blumenschein G Jr, Fayette J, Guigay J, Colevas AD, Licitra L, Harrington K, Kasper S, Vokes EE, Even C, Worden F, Saba NF, Iglesias Docampo LC, Haddad R, Rordorf T, Kiyota N, Tahara M, Monga M, Lynch M, Geese WJ, Kopit J, Shaw JW and Gillison ML: Nivolumab for recurrent squamous-cell carcinoma of the head and neck. N Engl J Med 375(19): 18561867, 2016. PMID: 27718784.

9 El-Khoueiry AB, Sangro B, Yau T, Crocenzi TS, Kudo M, Hsu C, Kim TY, Choo SP, Trojan J, Welling TH Rd, Meyer T, Kang YK, Yeo W, Chopra A, Anderson J, Dela Cruz C, Lang L, Neely J, Tang H, Dastani HB and Melero I: Nivolumab in patients with advanced hepatocellular carcinoma (CheckMate 040): An openlabel, non-comparative, phase $1 / 2$ dose escalation and expansion trial. Lancet 389(10088): 2492-2502, 2017. PMID: 28434648. DOI: $10.1016 /$ S0140-6736(17)31046-2

10 Overman MJ, McDermott R, Leach JL, Lonardi S, Lenz HJ, Morse MA, Desai J, Hill A, Axelson M, Moss RA, Goldberg MV, Cao ZA, Ledeine JM, Maglinte GA, Kopetz S, André T: Nivolumab in patients with metastatic DNA mismatch repairdeficient or microsatellite instability-high colorectal cancer (CheckMate 142): An open-label, multicentre, phase 2 study. Lancet Oncol 18(9): 1182-1191, 2017. PMID: 28734759. DOI: 10.1016/S1470-2045(17)30422-9

11 Le DT, Durham JN, Smith KN, Wang H, Bartlett BR, Aulakh LK, Lu S, Kemberling H, Wilt C, Luber BS, Wong F, Azad NS, Rucki AA, Laheru D, Donehower R, Zaheer A, Fisher GA, Crocenzi TS, Lee JJ, Greten TF, Duffy AG, Ciombor KK, Eyring AD, Lam BH, Joe A, Kang SP, Holdhoff M, Danilova L, Cope L, Meyer C, Zhou S, Goldberg RM, Armstrong DK, Bever KM, Fader AN, Taube J, Housseau F, Spetzler D, Xiao N, Pardoll DM, Papadopoulos N, Kinzler KW, Eshleman JR, Vogelstein B, Anders RA and Diaz LA Jr.: Mismatch repair deficiency predicts response of solid tumors to PD-1 blockade. Science 357(6349): 409-413, 2017. PMID: 28596308. DOI: 10.1126/science.an6733

12 Fuchs CS, Doi T, Jang RW, Muro K, Satoh T, Machado M, Sun W, Jalal SI, Shah MA, Metges JP, Garrido M, Golan T, Mandala M, Wainberg ZA, Catenacci DV, Ohtsu A, Shitara K, Geva R, Bleeker J, Ko AH, Ku G, Philip P, Enzinger PC, Bang YJ, Levitan D, Wang J, Rosales M, Dalal RP and Yoon HH: Safety and efficacy of pembrolizumab monotherapy in patients with previously treated advanced gastric and gastroesophageal junction cancer: Phase 2 clinical KEYNOTE-059 trial. JAMA Oncol 4(5): e180013, 2018. PMID: 29543932. DOI: 10.1001/jamaoncol.2018.0013

13 Abdel-Wahab N, Alshawa A and Suarez-Almazor ME: Adverse events in cancer immunotherapy. Adv Exp Med Biol 995: 155-174, 2017. PMID: 28321817. DOI: 10.1007/978-3-319-53156-4_8

14 Nagai $\mathrm{H}$ and Muto M: Optimal management of immune-related adverse events resulting from treatment with immune checkpoint inhibitors: A review and update. Int J Clin Oncol 223(3): 410420, 2018. PMID: 29516216. DOI: 10.1007/s10147-018-1259-6

15 Daniels GA, Guerrera AD, Katz D and Viets-Upchurch J: Challenge of immune-mediated adverse reactions in the emergency department. Emerg Med J 36(6): 369-377, 2019. PMID: 31113799. DOI: 10.1136/emermed-2018-208206

16 Saleh K, Khalife-Saleh N and Kourie HR: Do immune-related adverse events correlate with response to immune checkpoint inhibitors? Immunotherapy 11(4): 257-259, 2019. PMID: 30678551. DOI: 10.2217/imt-2018-0201 
17 Attia P, Phan GQ, Maker AV, Robinson MR, Quezado MM, Yang JC, Sherry RM, Topalian SL, Kammula US, Royal RE, Restifo NP, Haworth LR, Levy C, Mavroukakis SA, Nichol G, Yellin MJ and Rosenberg SA: Autoimmunity correlates with tumor regression in patients with metastatic melanoma treated with anticytotoxic T-lymphocyte antigen-4. J Clin Oncol 23(25): 60436053, 2005. PMID: 16087944. DOI: 10.1200/JCO.2005.06.205

18 Downey SG, Klapper JA, Smith FO, Yang JC, Sherry RM, Royal RE, Kammula US, Hughes MS, Allen TE, Levy CL, Yellin M, Nichol G, White DE, Steinberg SM and Rosenberg SA: Prognostic factors related to clinical response in patients with metastatic melanoma treated by CTL-associated antigen-4 blockade. Clin Cancer Res 13(22 pt 1): 6681-6688, 2007. PMID: 17982122. DOI: 10.1158/1078-0432.CCR-07-0187

19 Ascierto PA, Simeone E, Sileni VC, Pigozzo J, Maio M, Altomonte M, Del Vecchio M, Di Guardo L, Marchetti P, Ridolfi R, Cognetti F, Testori A, Bernengo MG, Guida M, Marconcini R, Mandalà M, Cimminiello C, Rinaldi G, Aglietta M and Queirolo P: Clinical experience with ipilimumab $3 \mathrm{mg} / \mathrm{kg}$ : Realworld efficacy and safety data from an Expanded Access Programme cohort. J Transl Med 12: 116, 2014. PMID: 24885479. DOI: $10.1186 / 1479-5876-12-116$

20 Horvat TZ, Adel NG, Dang TO, Momtaz P, Postow MA, Callahan MK, Carvajal RD, Dickson MA, D’Angelo SP, Woo KM, Panageas KS, Wolchok JD and Chapman PB: Immunerelated adverse events, need for systemic immunosuppression, and effects on survival and time to treatment failure in patients with melanoma treated with ipilimumab at Memorial Sloan Kettering Cancer Center. J Clin Oncol 33(28): 3193-3198, 2015. PMID: 26282644. DOI: 10.1200/JCO.2015.60.8448

21 Teulings HE, Limpens J, Jansen SN, Zwinderman AH, Reitsma JB, Spuls PI and Luiten RM: Vitiligo-like depigmentation in patients with stage III-IV melanoma receiving immunotherapy and its association with survival: A systematic review and metaanalysis. J Clin Oncol 33(7): 773-781, 2015. PMID: 25605840. DOI: $10.1200 / \mathrm{JCO} .2014 .57 .4756$

22 Gogas H, Ioannovich J, Dafni U, Stavropoulou-Giokas C, Frangia K, Tsoutsos D, Panagiotou P, Polyzos A, Papadopoulos O, Stratigos A, Markopoulos C, Bafaloukos D, Pectasides D, Fountzilas G and Kirkwood JM: Prognostic significance of autoimmunity during treatment of melanoma with interferon. $\mathrm{N}$ Engl J Med 354(7): 709-718, 2006. PMID: 16481638. DOI: 10.1007/s00281-011-0247-y

23 Boasberg PD, Hoon DS, Piro LD, Martin MA, Fujimoto A, Kristedja TS, Bhachu S, Ye X, Deck RR and O'Day SJ: Enhanced survival associated with vitiligo expression during maintenance biotherapy for metastatic melanoma. J Invest Dermatol 126(12): 2658-2663, 2006. PMID: 16946711. DOI: 10.1038/sj.jid.5700545

24 Fujisawa Y, Yoshino K, Otsuka A, Funakoshi T, Uchi H, Fujimura T, Matsushita S, Hata H, Okuhira H, Tanaka R, Nagai K, Ishida Y, Nakamura Y, Furudate S, Yamamura K, Imafuku K and Yamamoto Y: Retrospective study of advanced melanoma patients treated with ipilimumab after nivolumab: analysis of 60 Japanese patients. J Dermatol Sci 89(1): 60-66, 2018. PMID: 29079332. DOI: 10.1016/j.jdermsci.2017.10.009

25 Weber JS, Hodi FS, Wolchok JD, Topalian SL, Schadendorf D, Larkin J, Sznol M, Long GV, Li H, Waxman IM, Jiang J and Robert C: Safety profile of nivolumab monotherapy: a pooled analysis of patients with advanced melanoma. J Clin Oncol 35(7): 785-792, 2017. PMID: 28068177. DOI: 10.1200/JCO.2015.66.1389
26 Okada N, Kawazoe H, Takechi K, Matsudate Y, Utsunomiya R, Zamami Y, Goda M, Imanishi M, Chuma M, Hidaka N, Sayama K, Kubo Y, Tanaka A and Ishizawa K: Association between immune-related adverse events and clinical efficacy in patients with melanoma treated with nivolumab: A multicenter retrospective study. Clin Ther 41(1): 59-67, 2019. PMID: 30528047. DOI: $10.1016 / j$.clinthera.2018

27 Freeman-Keller M, Kim Y, Cronin H, Richards A, Gibney G and Weber JS: Nivolumab in resected and unresectable metastatic melanoma: Characteristics of immune-related adverse events and association with outcomes. Clin Cancer Res 22(4): 886-894, 2016. PMID: 26446948. DOI: 10.1158/1078-0432.CCR-15-1136

28 Maeda T, Yoshino K, Nagai K, Oaku S, Kato M, Hiura A and Hata H: Development of endocrine immune-related adverse events and improved survival in advanced melanoma patients treated with nivolumab monotherapy. Eur J Cancer 115: 13-16, 2019. PMID: 31082687. DOI: 10.1016/j.ejca.2019.04.005

29 Indini A, Di Guardo L, Cimminiello C, Prisciandaro M, Randon G, De Braud F and Del Vecchio M: Immune-related adverse events correlate with improved survival in patients undergoing anti-PD1 immunotherapy for metastatic melanoma. J Cancer Res Clin Oncol 145(2): 511-521, 2019. PMID: 30539281. DOI: 10.1007/s00432-018-2819-x

30 Bisschop C, Wind TT, Blank CU, Koornstra RHT, Kapiteijn E, Van den Eertwegh AJM, De Groot JWB, Jalving M and Hospers GAP: Association between pembrolizumab-related adverse events and treatment outcome in advanced melanoma: Results from the Dutch Expanded Access Program. J Immunother 42(6): 208-214, 2019. PMID: 31145233. DOI: 10.1097/CJI.0000000000000271

31 Hasan Ali O, Diem S, Markert E, Jochum W, Kerl K, French LE, Speiser DE, Früh M and Flatz L: Characterization of nivolumabassociated skin reactions in patients with metastatic non-small cell lung cancer. Oncoimmunology 5(11): e1231292, 2016. PMID: 27999741. DOI: 10.1080/2162402X.2016.1231292

32 Sato K, Akamatsu H, Murakami E, Sasaki S, Kanai K, Hayata A, Tokudome N, Akamatsu K, Koh Y, Ueda H, Nakanishi M and Yamamoto N: Correlation between immune-related adverse events and efficacy in non-small cell lung cancer treated with nivolumab. Lung Cancer 115: 71-74, 2018. PMID: 29290265. DOI: $10.1016 /$ j.lungcan.2017.11.019

33 Owen DH, Wei L, Bertino EM, Edd T, Villalona-Calero MA, He K, Shields PG, Carbone DP and Otterson GA: Incidence, risk factors, and effect on survival of immune-related adverse events in patients with non-small-cell lung cancer. Clin Lung Cancer 19(6): e893-e900, 2018. PMID: 30197259. DOI: 10.1016/j.cllc.2018.08.008

34 Haratani K, Hayashi H, Chiba Y, Kudo K, Yonesaka K, Kato R, Kaneda H, Hasegawa Y, Tanaka K, Takeda M and Nakagawa K: Association of immune-related adverse events with nivolumab efficacy in non-small cell lung cancer. JAMA Oncol 4(3): 374378, 2018. PMID: 28975219. DOI: 10.1001/jamaoncol.2017.2925

35 Teraoka S, Fujimoto D, Morimoto T, Kawachi H, Ito M, Sato Y, Nagata K, Nakagawa A, Otsuka K, Uehara K, Imai Y, Ishida K, Fukuoka $J$ and Tomii K: Early immune-related adverse events and association with outcome in advanced non-small cell lung cancer patients treated with nivolumab: A prospective cohort study. J Thorac Oncol 12(12): 1798-1805, 2017. PMID: 28939128. DOI: $10.1016 /$ j.jtho.2017.08.022

36 Ricciuti B, Genova C, De Giglio A, Bassanelli M, Dal Bello MG, Metro G, Brambilla M, Baglivo S, Grossi F and Chiari R: Impact of immune-related adverse events on survival in patients 
with advanced non-small cell lung cancer treated with nivolumab: Long-term outcomes from a multi-institutional analysis. J Cancer Res Clin Oncol 145(2): 479-485, 2019. PMID: 30506406. DOI: 10.1007/s00432-018-2805-3

37 Grangeon M, Tomasini P, Chaleat S, Jeanson A, SouquetBressand M, Khobta N, Bermudez J, Trigui Y, Greillier L, Blanchon $\mathrm{M}$, Boucekine $\mathrm{M}$, Mascaux $\mathrm{C}$ and Barlesi $\mathrm{F}$ : Association between immune-related adverse events and efficacy of immune checkpoint inhibitors in non-small-cell lung cancer. Clin Lung Cancer 20(3): 201-207, 2019. PMID: 30442524. DOI: 10.1016/j.cllc.2018.10.002

38 Osorio JC, Ni A, Chaft J, Pollina R, Kasler MK, Stephens D, Rodriguez C, Cambridge L, Rizvi H, Wolchok JD, Merghoub T, Rudin CM, Fish S and Hellmann MD: Antibody-mediated thyroid dysfunction during T-cell checkpoint blockade in patients with non-small-cell lung cancer. Ann Oncol 28(3): 583-589, 2017. PMID: 27998967. DOI: 10.1093/annonc/mdw640

39 Toi Y, Sugawara S, Kawashima Y, Aiba T, Kawana S, Saito R, Tsurumi K, Suzuki K, Shimizu H, Sugisaka J, Ono H, Domeki Y, Terayama K, Nakamura A, Yamanda S, Kimura Y and Honda Y: Association of immune-related adverse events with clinical benefit in patients with advanced non-small-cell lung cancer treated with nivolumab. Oncologist 23(11): 1358-1365, 2018. PMID: 29934411. DOI: 10.1634/theoncologist.2017-0384

40 Cortellini A, Chiari R, Ricciuti B, Metro G, Perrone F, Tiseo M, Bersanelli M, Bordi P, Santini D, Giusti R, Grassadonia A, Di Marino P, Tinari N, De Tursi M, Zoratto F, Veltri E, Malorgio F, Garufi C, Russano M, Anesi C, Zeppola T, Filetti M, Marchetti P, Berardi R, Rinaldi S, Tudini M, Silva RR, Pireddu A, Atzori F, Iacono D, Migliorino MR, Porzio G, Cannita K, Ficorella C and Buti S: Correlations between the immune-related adverse events spectrum and efficacy of anti-PD1 Immunotherapy in NSCLC patients. Clin Lung Cancer 20(4): 237-247, 2019. PMID: 30885550. DOI: 10.1016/j.cllc.2019.02.006

41 Ishihara H, Takagi T, Kondo T, Homma C, Tachibana H, Fukuda $\mathrm{H}$, Yoshida K, Iizuka J, Kobayashi H, Okumi M, Ishida H and Tanabe K: Association between immune-related adverse events and prognosis in patients with metastatic renal cell carcinoma treated with nivolumab. Urol Oncol 37(6): 355.e21-355.e29, 2019. PMID: 30935847. DOI: 10.1016/j.urolonc.2019.03.003

42 Verzoni E, Cartenì G, Cortesi E, Giannarelli D, De Giglio A, Sabbatini R, Buti S, Rossetti S, Cognetti F, Rastelli F, Sobrero A, Turci D, Sternberg CN, Porta C, Cappuzzo F, Tortora G, Tassinari D, Panni S, Pazzola A, Surico G, Raimondi A, De Giorgi U and Procopio G: Real-world efficacy and safety of nivolumab in previously-treated metastatic renal cell carcinoma, and association between immune-related adverse events and survival: The Italian Expanded Access Program. J Immunother Cancer 7(1): 99, 2019. PMID: 30944023. DOI: 10.1186/s40425019-0579-z
43 Billon E, Walz J, Brunelle S, Thomassin J, Salem N, Guerin M, Vicier C, Dermeche S, Albiges L, Tantot F, Nenan S, Pignot G and Gravis G: Vitiligo adverse event observed in a patient with durable complete response after nivolumab for metastatic renal cell carcinoma. Front Oncol 9: 1033, 2019. PMID: 31649889. DOI: $10.3389 /$ fonc. 2019.01033

44 Das S, Ciombor KK, Haraldsdottir S, Pumpalova Y, Sahin IH and Shyr Y: Immune checkpoint inhibitors (ICIs) in gastrointestinal (GI) cancer: Immune-related adverse events (IRAEs) and efficacy. J Clin Oncol 37(15): S4116, 2019. DOI: 10.1200/JCO.2019.37.15_suppl.4116

45 Masuda K, Shoji H, Nagashima K Yamamoto S, Ishikawa M, Imazeki H, Aoki M, Miyamoto T, Hirano H, Honma Y, Iwasa S7 Okita N, Takashima A, Kato K and Boku N: Correlation between immune-related adverse events and prognosis in patients with gastric cancer treated with nivolumab. BMC Cancer 19(1): 974, 2019. PMID: 31638948. DOI: 10.1186/s12885-019-6150-y

46 Foster CC, Kochanny S, Khattri A, Acharya R, Dekker A, Tan IHC, Klema E, Brisson RJ, Saloura V, Pearson AT, Vokes EE, Leidner RS, Mehanna HM and Seiwert TY: Association of immune-related adverse events (irAEs) with improved response, progression-free survival, and overall survival for patients with metastatic head and neck cancer receiving anti-PD-1 therapy. J Clin Oncol 36(15): 6014, 2018. DOI: 10.1200/JCO.2018.36.15_suppl.6014

47 Morales-Barrera R, Suarez Rodriguez C, Gonzalez M, Ros J, Semidey ME, Hernandez ES, Mateo J, Sáez CF, Lozano F, Mast R, Roche S, Quintana A, Gutiérrez Fernández S, Serrano C, Valverde C, de Torres I, Maldonado X, Morote J and Carles J: Impact of immune-related adverse events on survival in patients with metastastic urothelial carcinoma treated with immunecheckpoint inhibitors. J Clin Oncol 37(15): S4531, 2019. DOI: 10.1200/JCO.2019.37.15_suppl.4531

48 Maher VE, Fernandes LL, Weinstock C, Tang S, Agarwal S, Brave M, Ning YM, Singh H, Suzman D, Xu J, Goldberg KB, Sridhara R, Ibrahim A, Theoret M, Beaver JA and Pazdur R: Analysis of the association between adverse events and outcome in patients receiving a programmed death protein 1 or programmed death ligand 1 antibody. J Clin Oncol 37(30): 27302737, 2019. PMID: 31116675. DOI: 10.1200/JCO.19.00318
Received January 12, 2020

Revised January 21, 2020

Accepted January 24, 2020 